\title{
Mycoplasma bovis: Mechanisms of Resistance and Trends in Antimicrobial Susceptibility
}

\author{
Inna Lysnyansky ${ }^{1 *}$ and Roger D. Ayling ${ }^{2}$ \\ ${ }^{1}$ Mycoplasma Unit, Division of Avian and Aquatic Diseases, Kimron Veterinary Institute, Beit Dagan, Israel, ${ }^{2}$ Department of \\ Bacteriology, Animal and Plant Health Agency, Addlestone, UK
}

Mycoplasma bovis is a cell-wall-less bacterium and belongs to the class Mollicutes. It is the most important etiological agent of bovine mycoplasmoses in North America and Europe, causing respiratory disease, mastitis, otitis media, arthritis, and reproductive disease. Clinical disease associated with $M$. bovis is often chronic, debilitating, and poorly responsive to antimicrobial therapy, resulting in significant economic loss, the full extent of which is difficult to estimate. Until $M$. bovis vaccines are universally available, sanitary control measures and antimicrobial treatment are the only approaches that can be used in attempts to control M. bovis infections. However, in vitro studies show that many of the current $M$. bovis isolates circulating in Europe have high minimum

OPEN ACCESS

Edited by:

Gillberto Igrejas,

University of Trás-os-Montes and Alto

Douro, Portugal

Reviewed by:

Paul D. Brown,

University of the West Indies, Jamaica

Tanel X. Tenson,

University of Tartu, Estonia

*Correspondence:

Inna Lysnyansky

innal@moag.gov.il

Specialty section:

This article was submitted to Antimicrobials, Resistance and Chemotherapy,

a section of the journal

Frontiers in Microbiology

Received: 14 December 2015

Accepted: 11 April 2016

Published: 27 April 2016

Citation:

Lysnyansky I and Ayling RD (2016)

Mycoplasma bovis: Mechanisms of

Resistance and Trends in Antimicrobial Susceptibility. Front. Microbiol. 7:595.

doi: 10.3389/fmicb.2016.00595 inhibitory concentrations (MIC) for many of the commercially available antimicrobials. In this review we summarize the current MIC trends indicating the development of antimicrobial resistance in $M$. bovis as well as the known molecular mechanisms by which resistance is acquired.

Keywords: Mycoplasma bovis, minimum inhibitory concentrations, tetracyclines, macrolides, aminoglycosides, fluoroquinolones, chloramphenicols, pleuromutilins

\section{INTRODUCTION}

Mycoplasma bovis is a cell-wall-less bacterium and belongs to the class Mollicutes (Razin, 1978). It is the most important etiological agent of bovine mycoplasmosis in North America and Europe, causing respiratory disease, mastitis, otitis media, arthritis, and reproductive disease (Nicholas and Ayling, 2003). Until M. bovis vaccines are universally available, sanitary control measures and antimicrobial treatment are the only approaches that can be used in attempts to control M. bovis infections. However, M. bovis is refractory to ß-lactams and to all antimicrobials that target the cell wall. In addition, mycoplasmas are also naturally resistant to polymyxins, sulfonamides, trimethoprim, nalidixic acid, and rifampin (Taylor-Robinson and Bebear, 1997). Antimicrobials that are mycoplasmastatic provide an opportunity for the host's immune response to develop and counteract infection, but $M$. bovis has defense mechanisms that include an ability to vary its surface proteins (Lysnyansky et al., 1996) and form biofilms (McAuliffe et al., 2006).

The potential effectiveness of antimicrobials in vivo can be assessed by in vitro susceptibility testing to determine the minimum inhibition concentration (MIC). Guidelines for in vitro testing of veterinary mycoplasma species have been published (Hannan, 2000). However, the data produced are subject to interpretation as there are currently no in vitro testing standards and interpretive breakpoints have not been determined. Standards for testing Mollicutes that cause clinical infections in humans Mycoplasma pneumoniae, Mycoplasma hominis, and Ureaplasma urealyticum have 
been published (Waites et al., 2012). However, the growth requirements of these species differ from those of $M$. bovis. In addition, the authors are not aware of specific published $M$. bovis pharmacokinetics (PK)/pharmacodynamics (PD) studies which can influence the interpretation of in vitro antimicrobial sensitivity.

Herein, we review in vitro MIC data that indicate that $M$. bovis is developing antimicrobial resistance, which is increasingly being supported by molecular evidence of genetic mutations consistent with antimicrobial resistance and by reports of treatment failure.

\section{ANTIMICROBIAL CLASSES ACTIVE AGAINST M. BOVIS}

Control of $M$. bovis infection requires early identification and treatment with antimicrobials including the tetracyclines, macrolides and some fluoroquinolones. However, few are specifically approved for treating $M$. bovis in cattle and with the exception of the fluoroquinolones, which are mycoplasmacidal, and the aminoglycosides, which are mycoplasmacidal at high concentrations, the remaining antimicrobials are mycoplasmastatic, and generally work by inhibiting protein synthesis. The typical tetracyclines, chlortetracyline and doxycycline which are polycyclic structures of the perhydronaphthacene carboxamide inhibit protein synthesis in the ribosome by binding to the $30 \mathrm{~S}$ ribosomal subunit and blocking an attachment of aminoacyl-tRNA to the A site (Bryskier, 2005a). Other plasmid related resistance, or efflux mechanisms present in some Mycoplasma species have not been described in M. bovis.

The macrolides which are known to be good for treating respiratory infections have been shown to have a preferential distribution in vivo, concentrating in diseased lungs, up to three times the concentration detected in healthy lungs (ReeveJohnson, 1999). Macrolides are hydrophobic molecules that have a central 12-16-membered-ring lactone with few or no double bonds. They inhibit protein synthesis possibly by preventing peptidyltransferase from adding the growing peptide attached to tRNA to the next amino acid as well as inhibiting ribosomal translation. Another potential mechanism is premature dissociation of the peptidyl-tRNA from the ribosome. Macrolides can penetrate phagocytic cells thereby allowing treatment of intracellular infections. Lincosamides consist of an amino acid and a sugar connected by an amide bond. They act on the $50 \mathrm{~S}$ subunit of the ribosome, preventing transpeptidation by inhibiting peptidyl-transferase.

The fluoroquinolones are synthetic antimicrobials and all have a pyridine- $\beta$-carboxylic nucleus. Their activity depends on several factors: the aromatic system associated with the pyridineß-carboxylic acid nucleus, the substituents, and their spatial disposition. These substituents produce greater affinity for the target enzymes (DNA gyrase and topoisomerase IV) but also allow penetration of the bacterial outer membrane (Bryskier, 2005b). The activity of these antimicrobials can be affected by $\mathrm{pH}$, magnesium and calcium ions.
The aminoglycosides are amino sugars and fall into two broad groups based on their chemical structures: streptomycin and its derivatives and deoxystreptamines. The ribosome is the prime target of their action, but other actions on membranes and modifications of RNA synthesis have been observed. They are considered mycoplasmacidal, but that is concentration dependent.

The phenicols are derived from dichloroacetic acid with an aromatic nucleus and an alkyl group and an aminopropanediol chain. The fluoro derivative of chloramphenicol, florfenicol, is commonly used in the veterinary field. It inhibits protein synthesis by binding to the $50 \mathrm{~S}$ ribosomal subunit inhibiting the peptidation reaction and the translation of bacterial mRNA.

Pleuromutilins, such as tiamulin and valnemulin are semisynthetic derivatives that have a tricyclic diterpenoid structure with different side chains. They have been used in veterinary medicine; they bind to the peptidyl transferase component of the $50 \mathrm{~S}$ ribosomal subunit to inhibit protein synthesis (Long et al., 2006). Tiamulin was the first pleuromutilin compound to be approved for veterinary use in 1979, followed by valnemulin in 1999 (Novak and Shlaes, 2010).

\section{BOVIS IN VITRO SUSCEPTIBILITY PROFILES AND TRENDS}

M. bovis treatment failures are increasingly being associated with antimicrobial resistance. However, different research groups report variations in the proportion of $M$. bovis isolates with decreased susceptibility. This may be related to geographical origin, year of isolation, type of livestock production system, clinical presentation, or site of isolation of the strains tested. However, this may also indicate differences among the countries in regulatory practices for use of antimicrobials. Not all studies included epidemiology or typing of $M$. bovis isolates, but those which did, reported that in some countries the acquisition of resistance to antimicrobials in $M$. bovis was attributed to the emergence and spread of a single clone (Becker et al., 2015) while in other the genetic heterogeneity of $M$. bovis isolates with decreased susceptibility was identified (Lysnyansky et al., 2009).

$M$. bovis susceptibility testing has a role in epidemiological monitoring of acquired resistance and can guide the veterinarian in the selection of the most likely effective antimicrobial treatment, but published MIC data requires some interpretation, as there is no agreed standard method or controls for susceptibility testing of $M$. bovis. Although guidelines were produced by Hannan (2000), variations in the growth and approaches to determining the endpoint by different laboratories are reported and make it hard to compare results from different laboratories. However, these differences do not detract from the trends observed, which are now being supported by genetic evidence of resistance correlated with high MIC values (Lysnyansky et al., 2009; Sato et al., 2013; Lerner et al., 2014; Amram et al., 2015; Khalil et al., 2015). Nevertheless, standardized methods, controls and breakpoint interpretations would be highly beneficial for future epidemiology assessment of antimicrobial sensitivities and treatment guidance. In Table 1 we 
TABLE 1 | Minimal inhibitory concentration ranges $(\mu \mathrm{g} / \mathrm{ml})$ and $\mathrm{MIC}_{50}$ and $\mathrm{MIC}_{90}$ ranges for various antimicrobials against $M$. bovis ${ }^{\mathrm{a}}$.

\begin{tabular}{|c|c|c|c|}
\hline Antimicrobials & MIC ${ }^{b}$ Range & $\mathrm{MIC}_{50}$ Range & $\mathrm{MIC}_{90}$ Range \\
\hline \multicolumn{4}{|l|}{ Tetracyclines } \\
\hline Tetracycline & $<0.03->64$ & $1-8$ & $4-64$ \\
\hline Oxytetracycline & $0.05-128$ & $2-128$ & $4-128$ \\
\hline Chlortetracycline & $0.25-256$ & $2-128$ & $2-256$ \\
\hline Doxycycline & $\leq 0.03-1$ & 0.5 & 1 \\
\hline \multicolumn{4}{|l|}{ MLSK Group } \\
\hline Erythromycin & $4->512$ & $>3.2-512$ & $32-512$ \\
\hline Tylosin & $0.2->256$ & $1->128$ & $6.25->128$ \\
\hline Tilmicosin & $\leq 0.5->512$ & $2-512$ & $4->512$ \\
\hline Gamithromycin & $128->128$ & 128 & 128 \\
\hline Tildipirosin & $128->128$ & 128 & 128 \\
\hline Tulathromycin & $\leq 0.063->128$ & $0.25-128$ & $8->64$ \\
\hline Kitasamycin & $1-128$ & 4 & 64 \\
\hline Josamycin & $0.78-12.5$ & 1.56 & 6.25 \\
\hline Spiramycin & $0.39->100$ & 3.12 & 25 \\
\hline Lincomycin & $0.06->256$ & $0.78->64$ & $3.12->64$ \\
\hline Clindamycin & $0.03->256$ & $0.5-8$ & $>32$ \\
\hline Pirlimycin & $<0.125-0.5$ & 0.25 & 0.5 \\
\hline \multicolumn{4}{|l|}{ Pleuromutilins } \\
\hline Tiamulin & $<0.03-2$ & $0.06-0.2$ & $0.78-1$ \\
\hline Valnemulin & $<0.03$ & $<0.03$ & $<0.03$ \\
\hline \multicolumn{4}{|c|}{ Fluoroquinolones } \\
\hline Enrofloxacin & $0.025->32$ & $0.12-1$ & $0.12-32$ \\
\hline Danofloxacin & 0.078-32 & $0.156-0.5$ & $0.312-8$ \\
\hline Marbofloxacin & $0.25->32$ & $0.625-1.25$ & $0.625-32$ \\
\hline Flumequine & $16-128$ & 64 & 128 \\
\hline Ciprofloxacin & $0.125-1$ & 0.5 & 1 \\
\hline \multicolumn{4}{|c|}{ Aminoglycosides } \\
\hline Gentamycin & $2->64$ & 8 & 32 \\
\hline Kanamycin & $8->128$ & $32-64$ & $64->128$ \\
\hline \multicolumn{4}{|l|}{ Aminocyclitol } \\
\hline Spectinomycin & $0.03->256$ & $1->256$ & $2->256$ \\
\hline \multicolumn{4}{|c|}{ Chloramphenicols/Phenicols } \\
\hline Chloramphenicol & $0.25->32$ & $2-8$ & $2-32$ \\
\hline Thiamphenicol & $3.12->512$ & $6.25->512$ & $12.5->512$ \\
\hline Florfenicol & $0.06-64$ & $1-8$ & $2-32$ \\
\hline
\end{tabular}

a The data are compiled from multiple published studies (Ayling et al., 2000; Hirose et al., 2003; Thomas et al., 2003; Rosenbusch et al., 2005; Godinho, 2008; Gerchman et al., 2009; Uemura et al., 2010; Soehnlen et al., 2011; Kroemer et al., 2012; Hendrick et al., 2013; Ayling et al., 2014; Gautier-Bouchardon et al., 2014; Kawai et al., 2014; Sulyok et al., 2014; Kong et al., 2016) in which different methodologies (microbroth and agar dilution, but not E-test) and different antimicrobial concentrations were used (adapted from Bebear and Kempf, 2005; Waites et al., 2014).

${ }^{b}$ Only MIC data obtained for M. bovis isolated after 1990 were included.

present the susceptibility profiles (ranges of MICs, $\mathrm{MIC}_{50}$, and $\mathrm{MIC}_{90}$ ), obtained by microdilution and agar dilution methods, of $M$. bovis isolated in different countries since 1990. Both the $\mathrm{MIC}_{50}$ and $\mathrm{MIC}_{90}$ may indicate shifts in the susceptibility of bacterial populations to antimicrobials since $\mathrm{MIC}_{50}$ values show the general potency of an antimicrobial against a specific type of bacteria, while the $\mathrm{MIC}_{90}$ values indicates the potential and first stages of specific bacteria developing resistance to an antimicrobial.

\section{Tetracyclines}

In vitro susceptibility data from all over the world reveal heterogeneity in the susceptibility pattern to tetracyclines with $\mathrm{MIC}_{50}$ values for oxytetracycline ranging from 2 to $<8 \mu \mathrm{g} / \mathrm{ml}$ for isolates from Belgium, North America and Israel (Thomas et al., 2003; Rosenbusch et al., 2005; Gerchman et al., 2009; Soehnlen et al., 2011; Hendrick et al., 2013); while the $\mathrm{MIC}_{50}$ of isolates from the UK, the Netherlands, France, Hungry and Japan (Ayling et al., 2000, 2014; Hirose et al., 2003; Uemura et al., 2010; Gautier-Bouchardon et al., 2014; Kawai et al., 2014; Sulyok et al., 2014) was reported to be $\geq 8 \mu \mathrm{g} / \mathrm{ml}$. Notably, when susceptibility to tetracyclines was tested in two cohorts of respiratory $M$. bovis isolates isolated in the UK in 2004 and 2009 , a significant increase in the $\mathrm{MIC}_{50}$ from 1 to $32 \mu \mathrm{g} / \mathrm{ml}$ was identified (Ayling et al., 2014). In contrast, in France, the group of archived isolates (1978-1979) already demonstrated high MIC $_{50}$ to oxytetracycline $(32 \mu \mathrm{g} / \mathrm{ml})$, which increased to $\geq 32 \mu \mathrm{g} / \mathrm{ml}$ in recent isolates (2010-2012) (Gautier-Bouchardon et al., 2014). The authors suggested that less susceptible $M$. bovis isolates had developed by $1978-1979$.

\section{Macrolides and Lincosamides}

Acquired resistance to macrolides in $M$. bovis is a widely known phenomenon and isolates with high MICs are frequently identified (Table 1). For example, $\mathrm{MIC}_{50}$ values of $\geq 32 \mu \mathrm{g} / \mathrm{ml}$ for tilmicosin alone or for tylosin and tilmicosin were identified in recent British and Hungarian isolates (Ayling et al., 2014; Sulyok et al., 2014) as well as in isolates from western Canada, Japan and the USA (Rosenbusch et al., 2005; Uemura et al., 2010; Hendrick et al., 2013; Kawai et al., 2014). All recent French isolates had MICs of $\geq 64 \mu \mathrm{g} / \mathrm{ml}$ for tylosin and tilmicosin (Gautier-Bouchardon et al., 2014). Gerchman et al. (2009) reported marked differences in susceptibility profiles to tylosin and tilmicosin in isolates from different geographical regions. Israeli isolates were significantly more resistant to macrolides than isolates from calves imported from Hungary (2005-2007). However, recent Hungarian isolates (2010-2013) are more resistant to these antimicrobials $\left(\mathrm{MIC}_{50}\right.$ and $\left.\mathrm{MIC}_{90} \geq 128 \mu \mathrm{g} / \mathrm{ml}\right)$ (Sulyok et al., 2014). Such data emphasize the requirement for periodic antimicrobial susceptibility testing on a regional basis.

Both archived and recent French isolates possessed high MICs for the new-generation macrolides, gamithromycin and tildipirosin. In addition, all tested French isolates and $27 \%$ of British tested isolates had MIC values of $\geq 128 \mu \mathrm{g} / \mathrm{ml}$ to tulathromycin, a relatively new semi-synthetic macrolide (Ayling et al., 2014; Gautier-Bouchardon et al., 2014). Interestingly, results of a susceptibility study comparing MICs for tulathromycin in M. bovis respiratory isolates isolated in Europe prior to 2002 and between 2004 and 2006 showed an increase in $\mathrm{MIC}_{50}$ (from 0.25 to $4 \mu \mathrm{g} / \mathrm{ml}$ ) without a change in the $\mathrm{MIC}_{90}(>64 \mu \mathrm{g} / \mathrm{ml})$ (Godinho, 2008). The authors suggested that a high MIC does not necessarily reflect a lack of clinical efficacy of tulathromycin since an isolate with an MIC $>64 \mu \mathrm{g}$ 
$/ \mathrm{ml}$ was effectively treated in an experimental trial (Godinho et al., 2005; Godinho, 2008).

The $\mathrm{MIC}_{50}$ for lincomycin ranged from 0.78 to $\geq 64 \mu \mathrm{g} / \mathrm{ml}$ in several studies (Hirose et al., 2003; Thomas et al., 2003; Uemura et al., 2010; Ayling et al., 2014; Sulyok et al., 2014) and MIC $_{50}$ of $0.19 \mu \mathrm{g} / \mathrm{ml}$ (but with MIC $_{90}$ of $>256 \mu \mathrm{g} / \mathrm{ml}$; tested by $E$-test) for clindamycin were reported from Canada (Francoz et al., 2005). Interestingly, Ayling et al. (2014) reported decreased MIC $_{50}$ values for lincomycin (from 8 to $1 \mu \mathrm{g} / \mathrm{ml}$ ) and clindamycin (from $\geq 32$ to $0.25 \mu \mathrm{g} / \mathrm{ml}$ ) in $M$. bovis isolates isolated in the $\mathrm{UK}$ in 2004 and 2009. Low $\mathrm{MIC}_{50}$ and $\mathrm{MIC}_{90}$ of 0.25 and $0.5 \mu \mathrm{g} / \mathrm{ml}$, respectively for pirlimycin (Table 1) were reported in one study from Japan (Kawai et al., 2014).

\section{Fluoroquinolones}

In contrast to acquired resistance to macrolides which has been reported for a long time, the resistance to veterinary fluoroquinolones is a relatively new phenomenon. For example, only a single fold increase in $\mathrm{MIC}_{50}$ and $\mathrm{MIC}_{90}$ (in both cases from 0.25 to $0.5 \mu \mathrm{g} / \mathrm{ml}$ for enrofloxacin and danofloxacin; and from 0.5 to $1 \mu \mathrm{g} / \mathrm{ml}$ for marbofloxacin) was reported between 1978-1979 and 2010-2012 for French isolates (GautierBouchardon et al., 2014). The same increase in the $\mathrm{MIC}_{50}$ was also found in UK isolates isolated between 2004-2005 and during 2007-2009. However, their $\mathrm{MIC}_{90}$ values differed considerably $(0.5-1$ vs. $8->32 \mu \mathrm{g} / \mathrm{ml}$ ) (Ayling et al., 2014). Relatively low enrofloxacin $\mathrm{MIC}_{50}$ values of 0.12 to $0.5 \mu \mathrm{g} / \mathrm{ml}$ were reported in North America, Japan and some European countries (Hirose et al., 2003; Thomas et al., 2003; Rosenbusch et al., 2005; Uemura et al., 2010; Soehnlen et al., 2011; Hendrick et al., 2013; GautierBouchardon et al., 2014; Kawai et al., 2014; Sulyok et al., 2014). This may reflect differences in therapeutic use of antimicrobials in different countries.

\section{Aminocyclitol and Aminoglycosides}

Several studies have demonstrated relatively low $\mathrm{MIC}_{50}$ and $\mathrm{MIC}_{90}$ values for spectinomycin (up to $8 \mu \mathrm{g} / \mathrm{ml}$ ) (Rosenbusch et al., 2005; Uemura et al., 2010; Hendrick et al., 2013), while others reported that the difference between the $\mathrm{MIC}_{50}$ (1$8 \mu \mathrm{g} / \mathrm{ml})$ and $\mathrm{MIC}_{90}(>32 \mu \mathrm{g} / \mathrm{ml})$ was high (Ayling et al., 2000, 2014; Thomas et al., 2003; Soehnlen et al., 2011; Sulyok et al., 2014). In addition high $\mathrm{MIC}_{50}$ and high $\mathrm{MIC}_{90}(\geq 256 \mu \mathrm{g} / \mathrm{ml})$ values for spectinomycin were also reported (Ayling et al., 2000, 2014; Thomas et al., 2003; Soehnlen et al., 2011; Sulyok et al., 2014). Interestingly, higher spectinomycin MIC values have been reported for isolates from milk. Rosenbusch et al. (2005) reported that 6 out of 14 USA milk isolates had MIC values $>16 \mu \mathrm{g} / \mathrm{ml}$ while Soehnlen et al. (2011) reported a significant difference between $\mathrm{MIC}_{50}$ of milk $(>256 \mu \mathrm{g} / \mathrm{ml})$ and lung $(8 \mu \mathrm{g} / \mathrm{ml})$ isolates. MIC values for gentamycin ranged from 2 to $>64 \mu \mathrm{g} / \mathrm{ml}$ (Thomas et al., 2003; Sulyok et al., 2014) and kanamycin from 8 to $>128 \mu \mathrm{g} / \mathrm{ml}$ (Uemura et al., 2010; Kawai et al., 2014).

\section{Chloramphenicols}

The $\mathrm{MIC}_{50}$ values for florfenicol ranging from 1 to $8 \mu \mathrm{g} / \mathrm{ml}$ were identified in North America, Europe and China (Rosenbusch et al., 2005; Soehnlen et al., 2011; Hendrick et al., 2013; Kong et al., 2016). In addition, $M$. bovis isolates from Japan gave $\mathrm{MIC}_{50}$ values of $6.25-8 \mu \mathrm{g} / \mathrm{ml}$ and $6.25->512 \mu \mathrm{g} / \mathrm{ml}$ to chloramphenicol and thiamphenicol, respectively (Hirose et al., 2003; Uemura et al., 2010). Due to the potential toxicity of phenicols and chloramphenicols (not florfenicol), their use is now illegal in food animals in many countries (Papich and Riviere, 2013).

\section{Pleuromutilins}

The few MIC studies on tiamulin and valnemulin showed low MIC values for both antimicrobials (Table 1; Thomas et al., 2003; Gautier-Bouchardon et al., 2014). The efficacy of valnemulin against $M$. bovis infection was also demonstrated in vivo (Stipkovits et al., 2001, 2005).

\section{MOLECULAR MECHANISMS OF IN VIVO ACQUIRED RESISTANCE BY M. BOVIS}

In general, until now, the only mechanisms of acquired in vivo resistance described in Mollicutes are target modification and ribosome protection by the tet $(\mathrm{M})$ determinant (Bebear and Kempf, 2005).

\section{Tetracyclines}

The genetic background for decreased tetracycline susceptibility has been elucidated in greater detail in mycoplasmas of human origin than in M. bovis (reviewed by Waites et al., 2014). Ribosomal protection by tet(M) determinants in M. hominis and Ureaplasma spp. tetracycline-resistant isolates was identified (Roberts et al., 1985, 1986) while target modification with point mutation(s) in the 16S rRNA genes was described for in vitro obtained mutants of $M$. pneumoniae with MICs of $\leq 2 \mu \mathrm{g} / \mathrm{ml}$ (Degrange et al., 2008). Recent correlation between decreased susceptibility to tetracycline hydrochloride in $M$. bovis isolates and mutations identified in the primary binding pocket for tetracycline (Tet-1 site) located in 16S rRNA-encoding genes (rrs3 and rrs4 alleles) was shown (Amram et al., 2015). An increase in MICs to tetracycline (MICs $\geq 2 \mu \mathrm{g} / \mathrm{ml}$ ) was correlated with the number of mutated nucleotide positions within the Tet-1 site. Indeed, decreased susceptibilities to tetracycline were associated with mutations present at two (A965 and A967; E. coli numbering) or three positions (A965, A967, and G1058) in the two rrs alleles. No tet (M), tet (O), or tet $(\mathrm{L})$ determinants were identified in any of the $70 \mathrm{M}$. bovis isolates tested. Notably, no M. bovis isolates with high MICs $(\geq 32 \mu \mathrm{g} / \mathrm{ml})$ to tetracycline were available and tested in this study.

\section{Macrolides and Lincosamides}

Macrolide resistance in mollicutes, which have 1-3 ribosomal operons, is caused by point mutations of the macrolide-binding site located in the 23S rRNA genes or in the genes encoding ribosomal proteins L4 and L22 (reviewed by Waites et al., 2014). Recently, M. bovis decreased susceptibility to tylosin and tilmicosin was attributed to any one of the point mutations G748A, C752T, A2058G, A2059G, or A2059C (E. coli numbering) identified in one or both alleles of the $23 \mathrm{~S}$ rRNAs (Lerner et al., 2014). The data revealed that a combination of mutations in two domains (II and $\mathrm{V}$ of $23 \mathrm{~S}$ rRNA) was necessary to achieve higher MICs $(\geq 128 \mu \mathrm{g} / \mathrm{ml})$ to tylosin, while a single 
mutation in one of the domains could be sufficient to cause a decrease in susceptibility to this antimicrobial. In that study, amino acid (aa) substitution L22-Q90H (E. coli numbering) was also identified in 24 of 32 representative $M$. bovis isolates with different MICs, but no clear correlation between this mutation and decreased MICs to tylosin and tilmicosin was found. In addition, multiple aa substitutions were identified in the L4 protein, including at positions 185-186 (positions 64 and 65 in E. coli), which are adjacent to the macrolide-binding site (Lerner et al., 2014). However, the actual impact of L4 aa substitutions is hard to define since they were identified in isolates with various MICs, some of which also possessed nt substitution/s within the macrolide binding site of $23 \mathrm{~S}$ rRNA gene/s. Clarification of the role of mutations at positions 90-L22 and 64/or 64-65-L4 in decreased macrolide susceptibility by $M$. bovis is required.

\section{Fluoroquinolones}

The only mechanism of acquired fluoroquinolone resistance described in Mollicutes is alterations within the quinolone resistance-determining regions (QRDRs) of DNA gyrase subunits GyrA and GyrB and/or topoisomerase IV subunits ParC and ParE. However, an active efflux mechanism has also been demonstrated in vitro (Raherison et al., 2002). Amino acid substitution in the QRDR of GyrA (Ser83Phe) alone or with concurrent mutation Asn84Asp in ParC was found in $M$. bovis isolates with MICs to enrofloxacin ranging from $0.32-1.25$ to $2.5-5 \mu \mathrm{g} / \mathrm{ml}$, respectively (Lysnyansky et al., 2009). In another study, mutation Ser83Leu in GyrA was identified in 32 isolates with MICs of $0.25-2 \mu \mathrm{g} / \mathrm{ml}$ to enrofloxacin, orbifloxacin and danofloxacin; mutations in Ser83Leu of GyrA and Ser81Pro of ParC were present in three isolates $(4-16 \mu \mathrm{g} / \mathrm{ml})$ while mutations Ser83Phe in GyrA and Ser80Ile in ParC were found in four isolates $(8-16 \mu \mathrm{g} / \mathrm{ml})$ (Sato et al., 2013). The mutations Ser83Phe in GyrA and Ser80Ile in ParC were also identified in a Chinese $M$. bovis isolate with MICs $\geq 16 \mu \mathrm{g} / \mathrm{ml}$ to ciprofloxacin, levofloxacin, lomefloxacin and norfloxacin (Mustafa et al., 2013). In addition, Sato et al. (2013) showed that laboratory-derived fluoroquinolone-resistant mutants selected from two isolates with Ser83Leu in GyrA possessed an aa substitution Ser80Ile or Ser81Tyr in ParC. Results of both studies (Lysnyansky et al., 2009; Sato et al., 2013) suggest a cumulative effect of the mutations in GyrA and ParC on fluoroquinolone resistance. Previously, in vivo acquired resistance by veterinary mycoplasmas to the fluoroquinolones has been attributed to aa changes at positions 80 or 84 in the ParC as well as positions 83 in the GyrA (Hirose et al., 2004; Le Carrou et al., 2006; Vicca et al., 2007).

\section{REFERENCES}

Amram, E., Mikula, I., Schnee, C., Ayling, R. D., Nicholas, R. A. J., Rosales, R. S., et al. (2015). 16S rRNA gene mutations associated with decreased susceptibility to tetracycline in Mycoplasma bovis. Antimicrob. Agents Chemother. 59, 796-802. doi: 10.1128/AAC.03876-14

\section{Aminoglycosides}

No enzymes responsible for chemical modification of aminoglycosides have been identified in the $M$. bovis genome. However, decreased susceptibility to streptomycin in $M$. bovis was associated with nt $\mathrm{T}$ at position 912 (E. coli numbering) in the 16S rRNA genes (Konigsson et al., 2002), a position converting to resistance in E. coli (Frattali et al., 1990).

In an aminocyclitol antimicrobials, spectinomycin, isolates with high MIC ( $>512 \mu \mathrm{g} / \mathrm{ml})$ were found to exhibit a C to A transition at position 1192 (E. coli numbering) either in $r r s 3$ or in both rrs alleles (C. Schnee et al., abstract, IOM 2014, p. 60) as has been previously shown for spectinomycin-resistant $E$. coli (Sigmund et al., 1984).

\section{Chloramphenicols and Pleuromutilins}

To the best of our knowledge, no investigations of the phenicols /chloramphenicols and pleuromutilins resistance mechanisms for M. bovis have been published.

\section{SUMMARY}

Control of $M$. bovis infections in cattle is inherently difficult. The resulting clinical signs and disease are increasingly recognized as having a significant adverse impact on animal welfare and the economy of cattle farming around the world. Other than sanitary preventative measures, treatment with antimicrobials is the only approach for disease treatment. However, as emphasized herein, the number of potentially effective antimicrobials is limited as $M$. bovis lacks a cell wall. Among the few antimicrobials licensed for treatment of $M$. bovis, there is increasing evidence for resistance. Based on MIC levels and genetic analysis, antimicrobial resistance by $M$. bovis to the tetracyclines, macrolides, lincosamides, aminoglycosides, chloramphenicols, and fluoroquinolones has been reported and appears to be increasing. The mechanisms of $M$. bovis antimicrobial resistance have largely been based on genetic point mutations; few studies have examined efflux mechanisms and no plasmids have so far been detected in M. bovis.

This review highlights the necessity to agree a standardized method and controls for animal mycoplasma antimicrobial susceptibility testing. In addition breakpoints should be determined and the use of molecular resistance markers could be used to define them.

\section{AUTHOR CONTRIBUTIONS}

IL, RA designed the study and analyzed and interpreted data. IL, RA drafted the manuscript. All authors read and approved the final version of the manuscript.

Ayling, R. D., Baker, S. E., Peek, M. L., Simon, A. J., and Nicholas, R. A. (2000). Comparison of in vitro activity of danofloxacin, florfenicol, oxytetracycline, spectinomycin and tilmicosin against recent field isolates of Mycoplasma bovis. Vet. Rec. 146, 745-747. doi: 10.1136/vr.146.26.745

Ayling, R. D., Rosales, R. S., Barden, G., and Gosney, F. L. (2014). Changes in antimicrobial susceptibility of Mycoplasma bovis 
isolates from Great Britain. Vet Rec, 175, 486. doi: 10.1136/vr. 102303

Bebear, C. M., and Kempf, I. (2005). “Antimicrobial therapy and antimicrobial resistance," in Mycoplasmas: Molecular Biology, Pathogenicity and Strategies for Control, eds A. Blanchard and G. F. Browning (Norwich: Horizon Bioscience), 535-568.

Becker, C. A., Thibault, F. M., Arcangioli, M. A., and Tardy, F. (2015). Loss of diversity within Mycoplasma bovis isolates collected in France from bovines with respiratory diseases over the last 35 years. Infect Genet. Evol. 33, 118-126. doi: 10.1016/j.meegid.2015.04.019

Bryskier, A. (2005a). "Tetracyclines", in Antimicrobial Agents, Antibacterials and Antifungals, ed A. Bryskier (Washington, DC: ASM Press), 642-651.

Bryskier, A. (2005b). "Fluoroquinolones," in Antimicrobial Agents, Antibacterials and Antifungals, ed A. Bryskier (Washington, DC: ASM Press), 668-788.

Degrange, S., Renaudin, H., Charron, A., Pereyre, S., Bebear, C., and Bebear, C. M. (2008). Reduced susceptibility to tetracyclines is associated in vitro with the presence of 16S rRNA mutations in Mycoplasma hominis and Mycoplasma pneumoniae. J. Antimicrob. Chemother. 61, 1390-1392. doi: 10.1093/jac/ dkn118

Francoz, D., Fortin, M., Fecteau, G., and Messier, S. (2005). Determination of Mycoplasma bovis susceptibilities against six antimicrobial agents using the E test method. Vet. Microbiol. 105, 57-64. doi: 10.1016/j.vetmic.2004.10.006

Frattali, A. L., Flynn, M. K., De Stasio, E. A., and Dahlberg, A. E. (1990). Effects of mutagenesis of C912 in the streptomycin binding region of Escherichia coli 16 S ribosomal RNA. Biochim. Biophys. Acta 1050, 27-33. doi: 10.1016/01674781(90)90136-P

Gautier-Bouchardon, A. V., Ferre, S., Le Grand, D., Paoli, A., Gay, E., and Poumarat, F. (2014). Overall decrease in the susceptibility of Mycoplasma bovis to antimicrobials over the past 30 years in France. PLoS ONE 9:e87672. doi: 10.1371/journal.pone.0087672

Gerchman, I., Levisohn, S., Mikula, I., and Lysnyansky, I. (2009). In vitro antimicrobial susceptibility of Mycoplasma bovis isolated in Israel from local and imported cattle. Vet. Microbiol. 137, 268-275. doi: 10.1016/j.vetmic.2009.01.028

Godinho, K. S. (2008). Susceptibility testing of tulathromycin: interpretative breakpoints and susceptibility of field isolates. Vet. Microbiol. 129, 426-432. doi: 10.1016/j.vetmic.2007.11.033

Godinho, K. S., Rae, A., Windsor, G. D., Tilt, N., Rowan, T. G., and Sunderland, S. J. (2005). Efficacy of tulathromycin in the treatment of bovine respiratory disease associated with induced Mycoplasma bovis infections in young dairy calves. Vet. Ther. 6, 96-112.

Hannan, P. C. (2000). Guidelines and recommendations for antimicrobial minimum inhibitory concentration (MIC) testing against veterinary mycoplasma species. Vet. Res. 31, 373-395. doi: 10.1051/vetres:2000100

Hendrick, S. H., Bateman, K. G., and Rosengren, L. B. (2013). The effect of antimicrobial treatment and preventive strategies on bovine respiratory disease and genetic relatedness and antimicrobial resistance of Mycoplasma bovis isolates in a western Canadian feedlot. Can. Vet. J. 54, 1146-1156.

Hirose, K., Kawasaki, Y., Kotani, K., Abiko, K., and Sato, H. (2004). Characterization of a point mutation in the parC gene of Mycoplasma bovirhinis associated with fluoroquinolone resistance. J. Vet. Med. B 51, 169-175. doi: 10.1111/j.1439-0450.2004.00748.x

Hirose, K., Kobayashi, H., Ito, N., Kawasaki, Y., Zako, M., Kotani, K., et al. (2003). Isolation of mycoplasmas from nasal swabs of calves affected with respiratory diseases and antimicrobial susceptibility of their isolates. J. Vet. Med. B 50, 347-351. doi: 10.1046/j.1439-0450.2003.00681.x

Kawai, K., Higuchi, H., Iwano, H., Iwakuma, A., Onda, K., Sato, R., et al. (2014). Antimicrobial susceptibilities of Mycoplasma isolated from bovine mastitis in Japan. Anim. Sci. J. 85, 96-99. doi: 10.1111/asj.12144

Khalil, D., Becker, C. A., and Tardy, F. (2015). Alterations in the quinolone resistance-determining regions and fluoroquinolone resistance in clinical isolates and laboratory-derived mutants of Mycoplasma bovis: not all genotypes may be equal. Appl. Environ. Microbiol. 82, 1060-1068. doi: 10.1128/AEM.03280-15

Kong, L. C., Gao, D., Jia, B. Y., Wang, Z., Gao, Y. H., Pei, Z. H., et al. (2016). Antimicrobial susceptibility and molecular characterization of macrolide resistance of Mycoplasma bovis isolates from multiple provinces in China. J. Vet. Med. Sci. 78, 293-296. doi: 10.1292/jvms.15-0304
Konigsson, M. H., Bolske, G., and Johansson, K. E. (2002). Intraspecific variation in the 16S rRNA gene sequences of Mycoplasma agalactiae and Mycoplasma bovis strains. Vet. Microbiol. 85, 209-220. doi: 10.1016/S0378-1135(01)00517-X

Kroemer, S., Galland, D., Guerin-Faublee, V., Giboin, H., and Woehrle-Fontaine, F. (2012). Survey of marbofloxacin susceptibility of bacteria isolated from cattle with respiratory disease and mastitis in Europe. Vet. Rec. 170, 53. doi: 10.1136/vr.100246

Le Carrou, J., Laurentie, M., Kobisch, M., and Gautier-Bouchardon, A. V. (2006). Persistence of Mycoplasma hyopneumoniae in experimentally infected pigs after marbofloxacin treatment and detection of mutations in the parC gene. Antimicrob. Agents Chemother. 50, 1959-1966. doi: 10.1128/AAC.01527-05

Lerner, U., Amram, E., Ayling, R. D., Mikula, I., Gerchman, I., Harrus, S., et al. (2014). Acquired resistance to the 16-membered macrolides tylosin and tilmicosin by Mycoplasma bovis. Vet. Microbiol. 168, 365-371. doi: 10.1016/j.vetmic.2013.11.033

Long, K. S., Hansen, L. H., Jakobsen, L., and Vester, B. (2006). Interaction of pleuromutilin derivatives with the ribosomal peptidyl transferase center. Antimicrob. Agents Chemother. 50, 1458-1462. doi: 10.1128/AAC.50.4.14581462.2006

Lysnyansky, I., Mikula, I., Gerchman, I., and Levisohn, S. (2009). Rapid detection of a point mutation in the parC gene associated with decreased susceptibility to fluoroquinolones in Mycoplasma bovis. Antimicrob. Agents Chemother. 53, 4911-4914. doi: 10.1128/AAC.00703-09

Lysnyansky, I., Rosengarten, R., and Yogev, D. (1996). Phenotypic switching of variable surface lipoproteins in Mycoplasma bovis involves high-frequency chromosomal rearrangements. J. Bacteriol. 178, 5395-5401.

McAuliffe, L., Ellis, R. J., Miles, K., Ayling, R. D., and Nicholas, R. A. J. (2006). Biofilm formation by mycoplasma species and its role in environmental persistence and survival. Microbiology 152, 913-922. doi: 10.1099/mic.0. 28604-0

Mustafa, R., Qi, J., Ba, X., Chen, Y., Hu, C., Liu, X., et al. (2013). In vitro quinolones susceptibility analysis of Chinese Mycoplasma bovis isolates and their phylogenetic scenarios based upon QRDRs of DNA topoisomerases revealing a unique transition in ParC. Pak. Vet. J. 33, 364-369.

Nicholas, R. A., and Ayling, R. D. (2003). Mycoplasma bovis: disease, diagnosis, and control. Res. Vet. Sci. 74, 105-112. doi: 10.1016/S0034-5288(02) 00155-8

Novak, R., and Shlaes, D. M. (2010). The pleuromutilin antibiotics: a new class for human use. Curr Opin Investig Drugs, 11, 182-191.

Papich, M. G., and Riviere, J. E. (2013). "Chloramphenicol and derivatives, macrolides, lincosamides, and miscellaneous antimicrobials," in Veterinary Pharmacology and Therapeutics, eds J. E. Riviere and M. G. Papich (Iowa, IA: Wiley-Blackwell), 945-982.

Raherison, S., Gonzalez, P., Renaudin, H., Charron, A., Bebear, C., and Bebear, C. M. (2002). Evidence of active efflux in resistance to ciprofloxacin and to ethidium bromide by Mycoplasma hominis. Antimicrob. Agents Chemother. 46, 672-679. doi: 10.1128/AAC.46.3.672-679.2002

Razin, S. (1978). The mycoplasmas. Microbiol. Rev. 42, 414-470.

Reeve-Johnson, L. (1999). "The impact of mycoplasma infections in respiratory diseases of cattle in Europe," in Mycoplasma of Ruminants: Pathogenicity, Diagnostics, Epidemiology and Molecular Genetics, eds L. Stipkovits, R. Rosengarten, and J. Frey (Brussels: European Commision Press), $18-31$.

Roberts, M. C., Hillier, S. L., Hale, J., Holmes, K. K., and Kenny, G. E. (1986) Tetracycline resistance and tet $M$ in pathogenic urogenital bacteria. Antimicrob. Agents Chemother. 30, 810-812. doi: 10.1128/AAC.30.5.810

Roberts, M. C., Koutsky, L. A., Holmes, K. K., LeBlanc, D. J., and Kenny, G. E. (1985). Tetracycline-resistant Mycoplasma hominis strains contain streptococcal tetM sequences. Antimicrob. Agents Chemother. 28, 141-143. doi: 10.1128/AAC.28.1.141

Rosenbusch, R. F., Kinyon, J. M., Apley, M., Funk, N. D., Smith, S. C., and Hoffman, L. J. (2005). In vitro antimicrobial inhibition profiles of Mycoplasma bovis isolates recovered from various regions of the United States from 2002 to 2003. J. Vet. Diagn. Invest. 17, 436-441. doi: 10.1177/104063870501700505

Sato, T., Okubo, T., Usui, M., Higuchi, H., and Tamura, Y. (2013). Amino acid substitutions in GyrA and ParC are associated with fluoroquinolone resistance in Mycoplasma bovis isolates from Japanese dairy calves. J. Vet. Med. Sci. 75, 1063-1065. doi: 10.1292/jvms.12-0508 
Sigmund, C. D., Ettayebi, M., and Morgan, E. A. (1984). Antibiotic resistance mutations in $16 \mathrm{~S}$ and $23 \mathrm{~S}$ ribosomal RNA genes of Escherichia coli. Nucleic Acids Res. 12, 4653-4663. doi: 10.1093/nar/12.11.4653

Soehnlen, M. K., Kunze, M. E., Karunathilake, K. E., Henwood, B. M., Kariyawasam, S., Wolfgang, D. R., et al. (2011). In vitro antimicrobial inhibition of Mycoplasma bovis isolates submitted to the Pennsylvania Animal Diagnostic Laboratory using flow cytometry and a broth microdilution method. J. Vet. Diagn. Invest. 23, 547-551. doi: 10.1177/1040638711 404155

Stipkovits, L., Ripley, P. H., Tenk, M., Glavits, R., Molnar, T., and Fodor, L. (2005). The efficacy of valnemulin (EconorR) in the control of disease caused by experimental infection of calves with Mycoplasma bovis. Res. Vet. Sci. 78, 207-215. doi: 10.1016/j.rvsc.2004.09.005

Stipkovits, L., Ripley, P. H., Varga, J., and Palfi, V. (2001). Use of valnemulin in the control of Mycoplasma bovis infection under field conditions. Vet. Rec. 148, 399-402. doi: 10.1136/vr.148.13.399

Sulyok, M., Kreizinger, Z., Fekete, L., Hrivnak, V., Magyar, T., Janosi, S., et al. (2014). Antibiotic susceptibility profiles of Mycoplasma bovis strains isolated from cattle in Hungary, Central Europe. BMC Vet. Res. 10:256. doi: 10.1186/s12917-014-0256-x

Taylor-Robinson, D., and Bebear, C. (1997). Antibiotic susceptibilities of mycoplasmas and treatment of mycoplasmal infections. J. Antimicrob. Chemother. 40, 622-630. doi: 10.1093/jac/40. 5.622

Thomas, A., Nicolas, C., Dizier, I., Mainil, J., and Linden, A. (2003). Antibiotic susceptibilities of recent isolates of Mycoplasma bovis in Belgium. Vet. Rec. 153, 428-431. doi: 10.1136/vr.153.14.428
Uemura, R., Sueyoshi, M., and Nagatomo, H. (2010). Antimicrobial susceptibilities of four species of mycoplasma isolated in 2008 and 2009 from cattle in Japan. J. Vet. Med. Sci. 72, 1661-1663. doi: 10.1292/jvms.10-0165

Vicca, J., Maes, D., Stakenborg, T., Butaye, P., Minion, F., Peeters, J., et al. (2007). Resistance mechanism against fluoroquinolones in Mycoplasma hyopneumoniae field isolates. Microb. Drug Resist. 13, 166-170. doi: $10.1089 / \mathrm{mdr} .2007 .716$

Waites, K. B., Duffy, L. B., Bebear, C. M., Matlow, A., Talkington, D. F., Kenny, G. E., et al. (2012). Standardized methods and quality control limits for agar and broth microdilution susceptibility testing of Mycoplasma pneumoniae, Mycoplasma hominis, and Ureaplasma urealyticum. J. Clin. Microbiol. 50, 3542-3547. doi: 10.1128/JCM.01439-12

Waites, K. B., Lysnyansky, I., and Bébéar, C. M. (2014). "Emerging antimicrobial resistance in mycoplasmas of humans and animals," in Mollicutes: Molecular Biology and Pathogenesis, eds G. F. Browning and C. Citti (Norfolk,VA: Caister Academic Press), 289-322.

Conflict of Interest Statement: The authors declare that the research was conducted in the absence of any commercial or financial relationships that could be construed as a potential conflict of interest.

Copyright (C) 2016 Lysnyansky and Ayling. This is an open-access article distributed under the terms of the Creative Commons Attribution License (CC BY). The use, distribution or reproduction in other forums is permitted, provided the original author(s) or licensor are credited and that the original publication in this journal is cited, in accordance with accepted academic practice. No use, distribution or reproduction is permitted which does not comply with these terms. 